\title{
Altered Neocortical Rhythmic Activity States in Fmr1 K0 Mice Are Due to Enhanced mGluR5 Signaling and Involve Changes in Excitatory Circuitry
}

\author{
Seth A. Hays, Kimberly M. Huber, and Jay R. Gibson \\ Department of Neuroscience, University of Texas Southwestern Medical Center, Dallas, Texas 75390-9111
}

\begin{abstract}
Despite the pronounced neurological deficits associated with mental retardation and autism, the degree to which neocortical circuit function is altered remains unknown. Here, we study changes in neocortical network function in the form of persistent activity states in the mouse model of fragile X syndrome-the Fmrl knock-out (KO). Persistent activity states, or UP states, in the neocortex underlie the slow oscillation which occurs predominantly during slow-wave sleep, but may also play a role during awake states. We show that spontaneously occurring UP states in the primary somatosensory cortex are 38-67\% longer in Fmr1 K0 slices. In vivo, UP states reoccur with a clear rhythmic component consistent with that of the slow oscillation and are similarly longer in the Fmr1 KO. Changes in neocortical excitatory circuitry likely play the major role in this alteration as supported by three findings: (1) longer UP states occur in slices of isolated neocortex, (2) pharmacologically isolated excitatory circuits in Fmr1 KO neocortical slices display prolonged bursting states, and (3) selective deletion of Fmrl in cortical excitatory neurons is sufficient to cause prolonged UP states whereas deletion in inhibitory neurons has no effect. Excess signaling mediated by the group 1 glutamate metabotropic receptor, mGluR5, contributes to the longer UP states. Genetic reduction or pharmacological blockade of mGluR5 rescues the prolonged UP state phenotype. Our results reveal an alteration in network function in a mouse model of intellectual disability and autism which may impact both slow-wave sleep and information processing during waking states.
\end{abstract}

\section{Introduction}

Fragile X syndrome (FXS) is the most common form of inherited intellectual disability and is caused by loss of function mutations in FMR1 which encodes the RNA binding protein, FMRP (Verkerk et al., 1991; O’Donnell and Warren, 2002). Many of the impairments in FXS such as altered social responses and hypersensitivity to sensory stimuli are reproduced in the FXS mouse model, the Fmr1 knock-out (KO) mouse (The Dutch-Belgian Fragile X Consortium, 1994; Miller et al., 1999; Musumeci et al., 2000; Hagerman, 2002; Nielsen et al., 2002; Spencer et al., 2005; Brennan et al., 2006).

It has been hypothesized that altered cortical function mediates the cognitive and behavioral deficits in FXS (Irwin et al., 2001). In support of this idea, many cellular and synaptic alterations have been observed in cortical structures in FXS patients and in Fmr1 KO mice (for review, see Bassell and Warren, 2008; Pfeiffer and Huber, 2009).

Despite these numerous reported deficits, little electrophysiological evidence of alterations in cortical circuit function exists.

\footnotetext{
Received June 21, 2011; revised Aug. 10, 2011; accepted Aug. 12, 2011.

Author contributions: K.M.H. and J.R.G. designed research; S.H. performed research; S.H. and J.R.G. analyzed data; K.M.H. and J.R.G. wrote the paper.

This research was supported by National Institutes of Health Grants HD056370 (J.R.G.), NS045711 (K.M.H.), HD052731 (K.M.H.), and GM008203 (S.A.H.), and by Autism Speaks (K.M.H.). We thank Lorea Ormazabal for technical assistance with the mice. Gifts of mouse models are referenced in Materials and Methods.

Correspondence should be addressed to Jay R. Gibson, University of Texas Southwestern Medical Center, Department of Neuroscience, Box 9111, Dallas, TX 75390-9111. E-mail: Jay.Gibson@UTSouthwestern.edu.

DOI:10.1523/JNEUROSCI.3157-11.2011

Copyright $\odot 2011$ the authors $\quad 0270-6474 / 11 / 3114223-12 \$ 15.00 / 0$
}

There is a plasticity phenomenon in Fmrl KO mice where hippocampal networks become more excitable and epileptic in response to pharmacological blockade of inhibition (Chuang et al., 2005). However, it is unclear how cortical network function under basal conditions is altered in Fmrl KO mice. We have reported one such example where persistent activity states, or UP states, are longer in duration in neocortical slices obtained from Fmr1 KO mice when thalamic stimulation is used to induce the active state (Gibson et al., 2008). UP states are depolarized firing states of neurons that are driven by local recurrent excitation and inhibition, and occur synchronously among all neurons in a cortical region (Haider and McCormick, 2009; Sanchez-Vives et al., 2010). When they occur spontaneously and repeatedly, they underlie the neocortical "slow oscillation," which is a rhythm $(<1$ $\mathrm{Hz}$ ) occurring during slow-wave sleep, but they may also be involved in information processing during awake states (Steriade et al., 2001; Timofeev et al., 2001; Marshall et al., 2006; Haider and McCormick, 2009; Okun et al., 2010). Therefore, UP states are a critical aspect of neocortical circuit function, and understanding how and why they are altered in the Fmrl KO mouse would provide important information to how baseline neocortical circuit function is altered in fragile X syndrome. Such data would also provide specific strategies for treatment.

Questions remain about prolonged UP states in Fmr1 KO mice. First, while prolonged UP states are observed with thalamic stimulation (Gibson et al., 2008), are spontaneous and rhythmic UP states altered and are alterations intrinsic to neocortex? The answer to this is critical for linking prolonged UP states to possible 
alterations in the slow oscillation rhythm since neocortex has been hypothesized to primarily mediate the slow oscillation (Steriade, 1997; Haider and McCormick, 2009). Second, are UP states longer in the Fmr1 KO in vivo or is this strictly an in vitro slice phenomenon? Third, what is the relative role of changes in excitatory versus inhibitory circuitry? Fourth, what cellular processes lead to prolonged UP states?

We find that spontaneously occurring UP states are longer in the Fmrl KOboth in vitro and in vivo-and that this alteration involves changes in mGluR5 (group I metabotropic glutamate receptor) signaling in neocortical excitatory neurons.

\section{Materials and Methods}

Mice. Congenic Fmr1 KO mice on the C57BL6 background were originally obtained from Dr. Stephen Warren (Emory University, Atlanta, GA) and have been backcrossed onto the C57BL/6J mice from the University of Texas, Southwestern breeding core colony (The DutchBelgian Fragile X Consortium, 1994). Grm5 KO (mGluR5 KO) mice were obtained from Dr. Mark Bear (Massachusetts Institute of Technology, Cambridge, MA) but were made by another group (Lu et al., 1997). Emx1 Cre mice were obtained from Dr.Takuji Iwasato and Dr. Shigeyoshi Itohara (Riken BSI, Wako City, Saitama, Japan) (Iwasato et al., 2000, 2008) and Dlx5/6 Cre mice were obtained from Dr. Marc Ekker and Dr. John Rubinstein (University of California, San Francisco, California) (Monory et al., 2006). Floxed Fmr1 mice were obtained from Dr. David Nelson (Baylor College of Medicine, Houston, Texas) (Mientjes et al., 2006). All experiments were performed with littermate comparisons. Experimenters were blind to mouse genotype with respect to data depicted in Figures 1, 2, 5, and 6.

Slice preparation. Male mice, " 3 weeks" of age [postnatal days 18 (P18)-P24] were deeply anesthetized with Euthasol (pentobarbital sodium and phenytoin sodium solution) and decapitated. The brain was transferred into ice-cold dissection buffer containing (in $\mathrm{mm}$ ): $87 \mathrm{NaCl}, 3 \mathrm{KCl}, 1.25 \mathrm{NaH}_{2} \mathrm{PO}_{4}, 26 \mathrm{NaHCO}_{3}, 7$ $\mathrm{MgCl}_{2}, 0.5 \mathrm{CaCl}_{2}, 20 \mathrm{D}$-glucose, 75 sucrose, and 1.3 ascorbic acid aerating with $95 \% \mathrm{O}_{2}-5 \%$ $\mathrm{CO}_{2}$. Thalamocortical slices, $400 \mu \mathrm{m}$, were made on an angled block (Agmon and Connors, 1991) using a vibratome (Vibratome 1000 Plus). Following cutting, slices were transected parallel to the pia mater to remove the thalamus and midbrain. This transection was not done for the first experiment (see Fig. 1D,E and where indicated in corresponding text). Slices were immediately transferred to an interface recording chamber (Harvard Instruments) and allowed to recover for $1 \mathrm{~h}$ in nominal artificial CSF (ACSF) at $32^{\circ} \mathrm{C}$ containing (in mM): 126 $\mathrm{NaCl}, 3 \mathrm{KCl}, 1.25 \mathrm{NaH}_{2} \mathrm{PO}_{4}, 26 \mathrm{NaHCO}_{3}, 2$ $\mathrm{MgCl}_{2}, 2 \mathrm{CaCl}_{2}$, and 25 D-glucose. After this, slices were perfused with a modified ACSF that
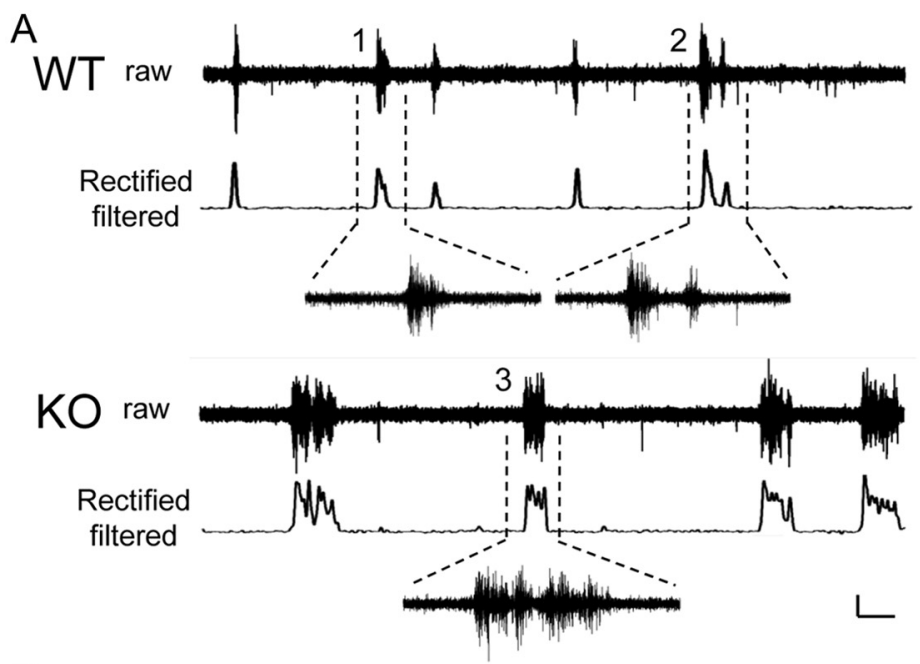

B

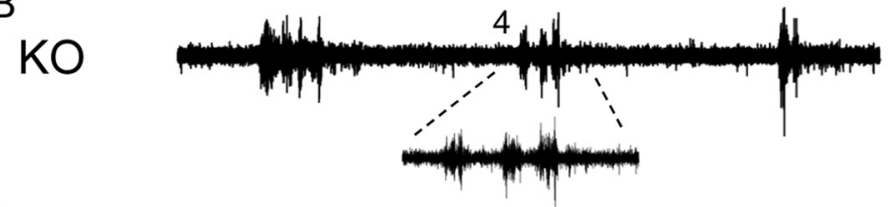

C

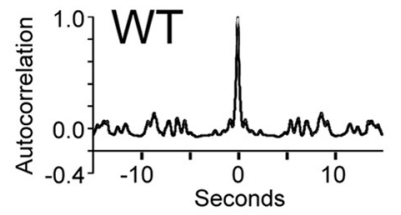

D

E

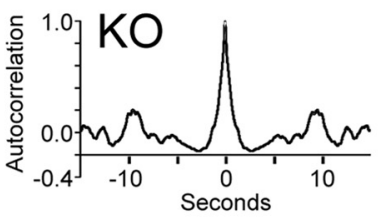

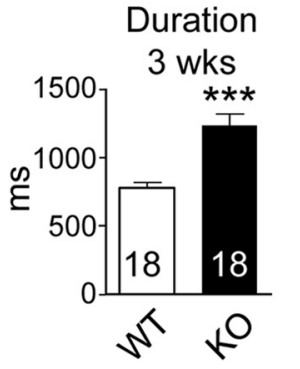

G

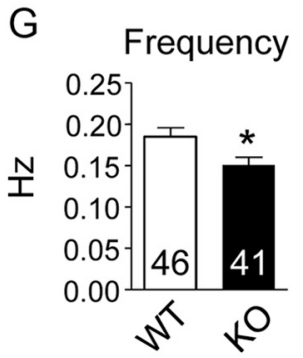

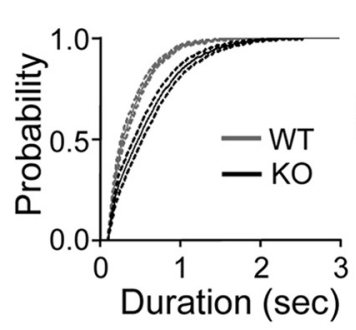

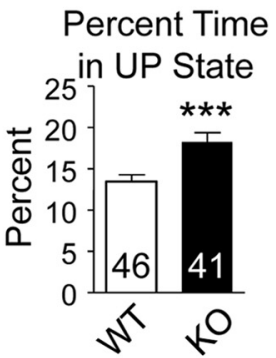

$\mathrm{F}$

UP State

Duration

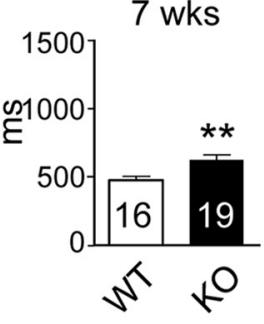

Figure 1. Spontaneously occurring persistent activity states, or UP states, are longer in layer 4 of $F m r 1 \mathrm{KO}$ somatosensory cortical slices. $A$, Examples of extracellular multiunit recordings from WT and KO slices demonstrate longer UP states in the K0. The rectified and filtered versions of the traces from which the UP states were analyzed are plotted underneath. Dashed lines indicate shorter epochs of the longer traces which are expanded to show more detail. $\boldsymbol{B}$, In some instances, UP states occurred in the form of closely spaced events, or bursts. These were considered one UP state (numbers 2 and 4 in $\boldsymbol{A}$ and $\boldsymbol{B}$; see Materials and Methods). C, Autocorrelograms from the examples in $\boldsymbol{A}$ reveal some rhythmic activity, but in general it was weak (see Materials and Methods for details of autocorrelograms). $\boldsymbol{D}$, Average UP state duration over all slices was higher in $\mathrm{K} 0$ slices at 3 weeks of age. $\boldsymbol{E}$, The average cumulative distribution of duration in a single slice (normalized for each slice and averaged over slices; same dataset as $\boldsymbol{C}$; see Materials and Methods) was evenly shifted to the right for the KO. Outer dashed lines represent the SE. $F$, Average UP state duration was still longer at 7 weeks of age. G, UP state frequency was decreased and percentage of time in the UP state increased. ${ }^{*} p<0.05$, ${ }^{* *} p<0.01,{ }^{* * *} p<0.001$. Calibrations: Vertical (in $\mu \mathrm{V}$ ), raw traces, 20; rectified, 0.1. Horizontal (in ms), long traces, 1500; short traces, 300. Numbers inside bars indicate slice number in all figures except Figures 3 and $6 D$. 
better mimics physiological ionic concentrations in vivo which contained (in $\mathrm{mm}$ ): $126 \mathrm{NaCl}, 5 \mathrm{KCl}, 1.25 \mathrm{NaH}_{2} \mathrm{PO}_{4}, 26 \mathrm{NaHCO}_{3}, 1 \mathrm{MgCl}_{2}, 1 \mathrm{CaCl}_{2}$, and 25 D-glucose (based on but modified from Sanchez-Vives and McCormick, 2000; Gibson et al., 2008). We used a slightly higher external $\mathrm{K}^{+}$concentration to promote active states ( $5 \mathrm{~mm}$ vs $3.5 \mathrm{~mm}$ in vivo), but this manipulation was probably unnecessary since the use of $3.5 \mathrm{~mm}$ external $\mathrm{K}^{+}$ still results in spontaneously generated UP states (Rigas and CastroAlamancos, 2007). Slices remained in this modified ACSF for $45 \mathrm{~min}$ and then recordings were performed with the same modified ACSF.

$U P$ state recordings and analysis. Spontaneously generated UP states in vitro were extracellularly recorded using $0.5 \mathrm{M} \Omega$ tungsten microelectrodes (FHC) placed in layer 4 of primary somatosensory cortex. This extracellular monitoring of UP states is a reliable indicator of the synchronous, depolarized state of neuron populations from which the term "UP state" was originally defined (Sanchez-Vives and McCormick, 2000; Rigas and Castro-Alamancos, 2007). As indicated, some recordings were performed in layer 5. A total of $10 \mathrm{~min}$ of spontaneous activity was collected from each slice. For drug wash-on experiments, data were collected for $70 \mathrm{~min}$. Recordings were amplified 10,000-fold, sampled at 2.5 $\mathrm{kHz}$, and filtered on-line between $500 \mathrm{~Hz}$ and $3 \mathrm{kHz}$. All measurements were analyzed off-line using custom Labview software. For visualization and analysis of UP states, traces were offset to zero, rectified, and lowpass filtered with a $0.2 \mathrm{~Hz}$ cutoff frequency. Using these processed traces, the threshold for detection was set at $4 \times$ the RMS (root mean square) noise $(5 \times$ for picrotoxin + CGP55845 experiments; see Fig. 4 ), and an event was defined as an UP state if its amplitude remained above the threshold for at least $200 \mathrm{~ms}$. The end of the UP state was determined when the amplitude decreased below threshold for $>600 \mathrm{~ms}$. Two events occurring within $600 \mathrm{~ms}$ of one another were grouped as a single UP state. These criteria best accounted for the simultaneous occurrence and identical durations of UP states in layers 4 and 5 (Fig. 2). Our main finding of longer UP states in Fmr1 KO mice (Fig. 1) was not strictly dependent on these criteria since the same result was obtained with no grouping of events and with different detection thresholds. UP state amplitude was defined based on the filtered/rectified traces and was unitless since it was normalized to the detection threshold. This amplitude may be considered a coarse indicator of the underlying firing rates of neuronal populations. Direct measures of firing rates were not possible because individual spikes could not be isolated except during the quiet periods (the DOWN states). Data are represented by the mean \pm SEM and values. Significant differences were determined using $t$ tests, one-way ANOVA, two-way ANOVA, or three-way ANOVA where appropriate (all performed with GraphPad Prism 5 except for the three-way which was performed with Sigmaplot). Repeated-measures ANOVA was also used when appropriate. Bonferroni post hoc tests were performed following ANOVAs. Sample number $(n)$ is slice or mouse number-the latter for in vivo experiments. For all slice experiments, a minimum of 4 mice were used per condition, and on average, 4 slices were examined per mouse.

For cumulative distributions of UP state durations, a normalized cumulative distribution was obtained for each experiment (data from one slice or for in vivo experiments, from one mouse), where $y$ values were interpolated for predetermined points of the $x$-axis. This enabled the calculation of an average and SD based on experiment, where sample number refers to either slice number or mouse number (the latter for in vivo). A KolmogorovSmirnov test was performed for statistical analysis. This method equalizes the contribution to the distribution made by each experiment.

Autocorrelations were performed on rectified and filtered traces for 300 and $60 \mathrm{~s}$ epochs for slices and in vivo recordings, respectively. Autocorrelations were normalized to the variance resulting in a peak of 1 at time 0 . To measure rhythmicity, we measured the side-peaks of the autocorrelogram by averaging the two peak-to-trough distances from each side of the peak.

Group I $m$ GluR antagonist and protein synthesis inhibitor pretreatment. As stated above, slices underwent an initial $1 \mathrm{~h}$ incubation in nominal ACSF. Like other experiments, slices were then exposed to the "modified" ACSF for the next $45 \mathrm{~min}$, but in experiments using mGluR antagonists, this latter period included the pretreatment with the antagonist in the ACSF. In experiments inhibiting protein synthesis, this latter period included pretreatment with anisomycin $(20 \mu \mathrm{M})$. The antagonist or ani-
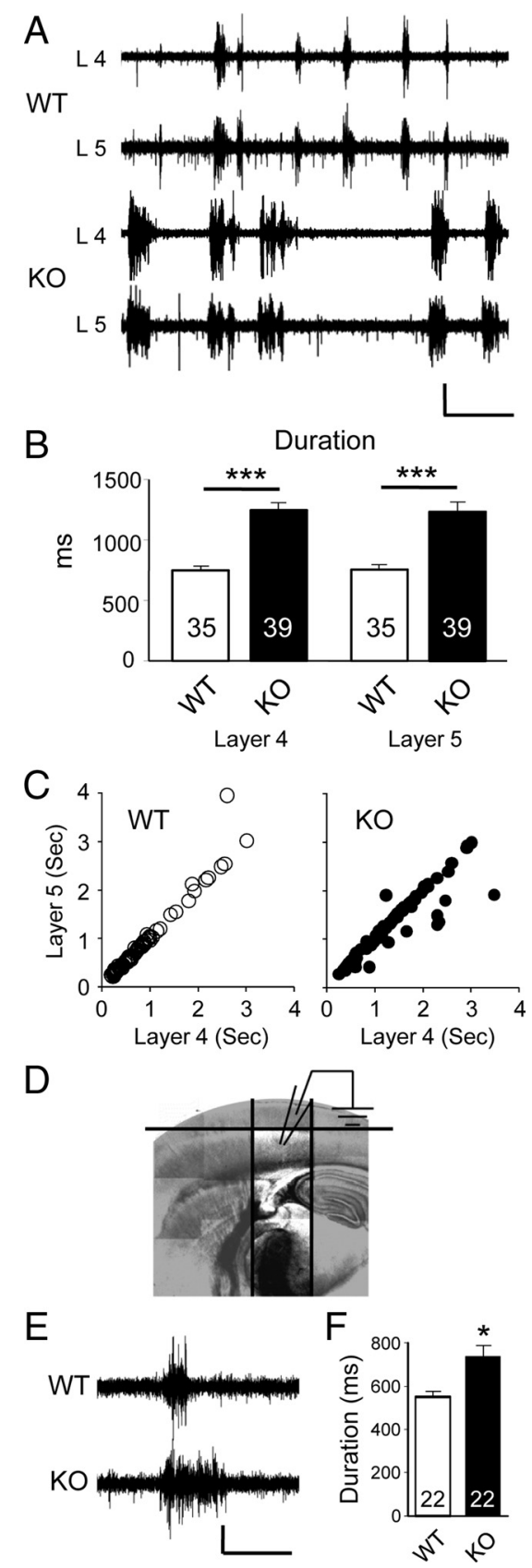

Figure 2. Spontaneously occurring UP states are longer in layer 5. $\boldsymbol{A}$, Examples of simultaneous multiunit recordings of layers $4(\mathrm{~L} 4)$ and $5(\mathrm{~L} 5)$ in a WT and a KO slice. $\boldsymbol{B}$, The longer duration phenotype in Fmr $1 \mathrm{KO}$ slices also exists to the same extent in both layers 4 and 5. C, Scatter plots depicting UP state durations measured in a single experiment from a WT and a KO slice. Each point represents the duration of a single UP state measured simultaneously in layer 4 and 5. Note the strong correlation. $D$, A picture depicting a slice that was used for recording from deep neocortical layers in isolation. Gray shading indicates regions removed. $\boldsymbol{E}$, UP states recorded in layer 5 of slices containing only deep layers. $\boldsymbol{F}$, Isolated deep layers of neocortex display longer UP states in Fmr1 K0 slices. ${ }^{*} p<0.05,{ }^{* * *} p<0.001$. Calibrations: (A) $30 \mu \mathrm{V}$, $5 \mathrm{~s} ;(\boldsymbol{E}) 30 \mu \mathrm{V}, 1 \mathrm{~s}$.

somycin remained in the ACSF for the remainder of the experimentincluding the recording periods. The pretreatment experimental design, as opposed to application while recording, enabled us to examine many more slices in a single experiment since slices were stored and recorded from the same chamber (see Slice preparation above). More recordings meant that we obtained more accurate UP state duration values (which varied a few hundred milliseconds from one experiment to the next) and meant that we could more readily detect $35-50 \%$ changes in UP state 
duration among the 8 groups compared in the mGluR antagonist experiments (see Fig. 7B). The preincubation time was selected because previous studies have shown the mGluR-regulated protein synthesis has electrophysiological effects on this time scale. The mGluR antagonists were the mGluR5-selective antagonist, MPEP $(10 \mu \mathrm{M})$, and the mGluR1selective antagonist, LY367385 (100 $\mu \mathrm{M})$.

Recordings in vivo. Three- to 4-week-old mice were anesthetized with urethane $(1.5 \mathrm{~g} / \mathrm{kg}, 20 \%$ solution in distilled water) supplemented with isoflurane $\left(1.5 \%, 1.5 \mathrm{~L} / \mathrm{min} \mathrm{O}_{2}\right.$ flow) and placed in a stereotaxic apparatus with anesthetic maintained. A scalp incision was performed and a craniotomy performed at $2 \mathrm{~mm}$ posterior to bregma and $2.5 \mathrm{~mm}$ lateral to midline. An extracellular recording electrode (same as described for in vitro) was inserted into the craniotomy and advanced to approximately layer 4 and layer 5 of cortex as confirmed with lesions observed after brain fixation. At this point, isoflurane application was stopped, and recordings were performed for 20-30 min. Health and depth of anesthesia were monitored by body temperature, heart rate, respiratory rate, tail pinch reflex, and by the clear occurrence of cycling between UP and DOWN states. Any indication of a lighter anesthesia plane resulted in additional injection of urethane. Immediately after recording, the mouse was killed with an overdose of Euthasol (pentobarbital sodium and phenytoin sodium solution).

Immunohistochemistry. Immunohistochemistry was performed on progeny of Cre (Emx1 and Dlx5/6 Cre) and floxed Fmr1 mice to confirm cell type-specific deletion of Fmr1. Mice (P21-P24) were perfused with cold PBS followed by $4 \%$ paraformaldehyde $(\mathrm{w} / \mathrm{v})$. The brain was removed and resectioned into $80 \mu \mathrm{m}$ slices. Antigen retrieval was performed by placing the slices into warm $200 \mathrm{~mm}$ sodium citrate and microwaving for $1 \mathrm{~min}$ at low power. The slices were blocked for $1 \mathrm{~h}$ at room temperature in PBS with 3\% normal goat serum and $0.5 \%$ Triton-X. Primary antibodies were dissolved in blocking solution and applied overnight at $4^{\circ} \mathrm{C}$. Secondary antibodies were dissolved in blocking solution and applied for $1 \mathrm{~h}$ at room temperature. Primary antibodies used were mouse anti-FMRP (2F5, 1:200, gift from Dr. Jennifer Darnell, Rockefeller University, New York, NY) and rabbit anti-GABA (A2052, 1:1000, Sigma). The specificity of $2 \mathrm{~F} 5$ has been demonstrated previously (Gabel et al., 2004) and by our comparison of labeling in Fmrl KO versus WT tissue. Specificity of A2052 has been demonstrated previously (Stevens et al., 2010) and in this study, its labeling was consistent with our use of the DLX5/6 Cre mouse which is GABAergic neuron specific (see Fig. 5; FMRP was deleted only in GABAergic neurons) (Monory et al., 2006). Secondary antibodies used were goat anti-mouse 555 and goat antirabbit 488 (1:250, Sigma).

Reagents. Drugs were prepared as stocks and stored at $-20^{\circ} \mathrm{C}$ and used within 2 weeks. The mGluR1-selective antagonist $(S)-(+)$ - $\alpha$-amino-4carboxy-2-methylbenzeneacetic acid (LY367385,100 $\mu \mathrm{M}$ ), the mGluR5selective antagonist MPEP $(10 \mu \mathrm{M})$, the protein translation inhibitor, anisomycin $(20 \mu \mathrm{M})$, the $\mathrm{GABA}_{\mathrm{B}}$ receptor antagonist, CGP55845 $(1 \mu \mathrm{M})$, and the mixed group I mGluR agonist $(R, S)$-3,5-dihydroxyphenylglycine (DHPG, $10 \mu \mathrm{M}$ ) were purchased from Tocris Bioscience (Ellisville, $\mathrm{MO})$. The $\mathrm{GABA}_{\mathrm{A}}$ receptor antagonist, picrotoxin $(100 \mu \mathrm{M})$, was purchased from Sigma. Drugs required 12-18 min upon start of application to reach and perfuse the slice at the steady-state concentration due to delays in the perfusion system.

\section{Results \\ Spontaneously occurring UP states are longer in layer 4 of Fmr1 KO slices}

Spontaneously generated active states, or UP states, were measured in acute neocortical slices obtained from 3- to 4-week-old WT and Fmr1 KO mice. UP states were measured with extracellular, multiunit recordings in layer 4 , and then analyzed after rectification and low-pass filtering of the recorded traces (Fig. $1 A$; see Materials and Methods). Activity in both WT and KO slices sometimes occurred in closely associated bursts that we grouped together as a single UP state in our analysis (Fig. $1 A_{2}, B_{4}$; see Materials and Methods). UP states in some slice recordings were not observably rhythmic, but in other recordings, were weakly rhythmic. This weak rhythmicity was observed by autocorrelograms of the rectified, filtered traces (Fig. 1C).

Similar to thalamically evoked activity states (Gibson et al., 2008), the duration of spontaneously occurring UP states observed in Fmr1 KO slices was increased by 59\% compared with WT (Fig. $1 D, E ; 777 \pm 39$ vs $1236 \pm 85$ ms, $p<0.001$; WT,KO; $n=18,18$ slices). While this analysis was performed by detecting discrete UP states (see Materials and Methods), the altered spontaneous activity could also be observed by another independent method that did not rely on our detection of UP states-the autocorrelation of the rectified, filtered traces. The width at halfheight of the autocorrelation function was 54\% larger for traces obtained from KO slices (Fig. 1C; $302 \pm 25$ vs $466 \pm 50 \mathrm{~ms}, p<$ 0.05 ; WT, KO), consistent with the longer duration UP states in the KO. Slices in these initial experiments contained the thalamus and its connections with neocortex, and therefore it was possible that the thalamus might be playing a role in the longer UP states. This was not the case since all successive experiments were performed with all subcortical regions removed, and UP states were still longer to the same extent (see controls in Figs. 5-8). The abnormally long UP states persist at later ages ( 7 weeks) since KO slices obtained from older animals, 7-8 weeks of age, also had longer UP states although the difference was not as pronounced (Fig. $1 F$; $489 \pm 29$ vs $640 \pm 38 \mathrm{~ms}, p<0.01$; WT,KO; $n=16,19$ slices).

We examined other UP state characteristics in 3-week-old slices by adding control data from another experiment (see controls in Fig. $6 ; n=46,41$ ). In addition to duration being similarly longer in this larger dataset ( $67 \%$ increase; $761 \pm 37$ vs $1274 \pm 57$ $\mathrm{Hz}, p<0.001$; WT,KO), we were able to detect an $18 \%$ decrease in UP state frequency (Fig. $1 G ; 0.185 \pm 0.011$ vs $0.151 \pm 0.013$ $\mathrm{Hz}, p<0.05$; WT,KO) and a $35 \%$ increase in the percentage of time spent in the UP state $(13.5 \pm 0.8$ vs $18.2 \pm 1.1 \%, p<0.001$; $\mathrm{WT}, \mathrm{KO})$. The number of bursts within an UP state was also increased by $29 \%(1.68 \pm 0.04$ vs $2.16 \pm 0.09$ bursts, $p<0.001$; $\mathrm{WT}, \mathrm{KO}$ ), but this did not completely account for the $67 \%$ increase in duration. We detected no change in the normalized amplitude of UP states as defined by our rectified, filtered traces (5.4 \pm 0.4 vs $6.4 \pm 0.5, p=0.08$; WT,KO; see Materials and Methods) which may reflect no change in the underlying intensity of action potential firing that occurs during UP states. In summary, while a number of characteristics of UP states may be altered in Fmr1 $\mathrm{KO}$ slices, the duration increase was the most salient.

\section{UP states are longer in layer 5}

On the scale of seconds, UP states occur approximately simultaneously in all layers in a local neocortical circuit, but on the scale of 10-150 ms, differences in onset and duration across layers are observed (Sanchez-Vives and McCormick, 2000; Chauvette et al., 2010). Therefore, it was not clear whether the longer UP states we observed in layer 4 of Fmr1 KO slices represented a more general phenomenon across all layers. With all the layer 4 recordings depicted in Figure 1, we simultaneously recorded from layer 5 (Fig. $2 A, n=35,39$ ). Average UP state duration in layer 5 was not different from that recorded in layer 4 in the same slice. Also, layer 5 UP state duration was longer in Fmr1 KO compared with WT slices (Fig. $2 B, 756 \pm 34$ vs $1233 \pm 83 \mathrm{~ms}, p<0.001$; $\mathrm{WT}, \mathrm{KO})$. UP states in a single slice vary in duration, and the length of a single UP state in one layer was strongly correlated with the length in the other layer when examining the interlayer correlation of UP state durations in a single experiment (Fig. 2C; correlation for durations, WT: $r=0.83 \pm 0.07$; KO: $r=0.84 \pm$ $0.03 ; n=6,8)$. There was spontaneous unit activity during the quiet states (or DOWN states) in layer 5 as previously reported 


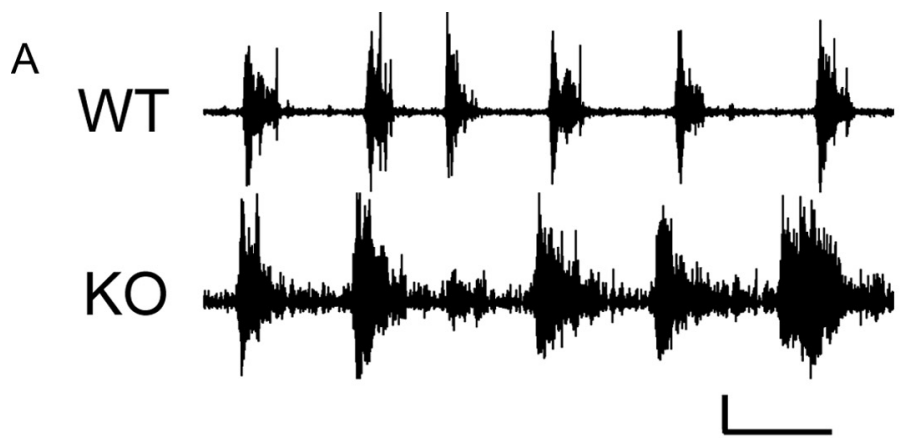

B Duration
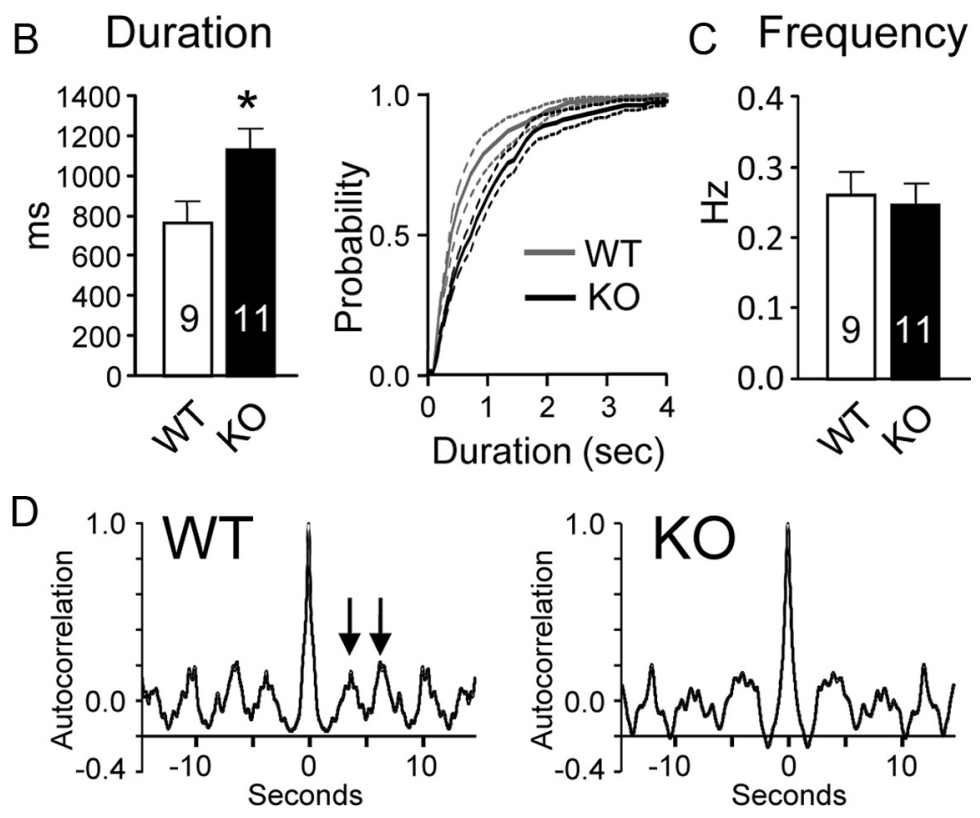

Figure 3. UP states are longer in Fmr1 KO mice, in vivo. $A$, Examples of multiunit recordings from single WT and $\mathrm{KO}$ mice, in vivo. $\boldsymbol{B}$, Average duration of UP states is longer in Fmr $1 \mathrm{KO}$ mice (numbers inside bars indicate mouse number). An average cumulative histogram (right) indicates an even shift in durations across all animals (normalized for each mouse and averaged over mice, same dataset as bar graph to the left; see Materials and Methods). Outer dashed lines are SE. C, The frequency of UP states was not detectably different. $\boldsymbol{D}$, Autocorrelations of the filtered, rectified traces depicted in $\boldsymbol{A}$ reveal a clear rhythmic component of the activity probably reflecting the slow oscillation (see Materials and Methods for details of autocorrelograms). Examples of first and second side-peaks are marked by arrows. ${ }^{*} p<0.05$. Calibrations: $50 \mu \mathrm{V}, 3 \mathrm{~s}$.

(Sanchez-Vives and McCormick, 2000), and we observed this in both WT and $\mathrm{KO}$ slices with no detected differences in spike frequency (Fig. $2 A ; 0.92 \pm 0.12$ vs $0.96 \pm 0.09 \mathrm{~Hz}$; WT,KO; $n=16,16$ ).

A cross-correlation analysis of the rectified/filtered traces (not durations as in Fig. 2C) was performed on layer 4 and 5 recordings for each slice, and this indicated a high average correlation $(r=0.88 \pm 0.02$ vs $0.92 \pm 0.01, p<0.05$; WT, KO) and a slight delay in the layer 4 signals relative to layer 5 (12.7 \pm 1.4 vs $13.7 \pm$ $1.5 \mathrm{~ms}$; WT,KO). The delay is consistent with earlier studies indicating that UP states are initiated in layer 5 (Sanchez-Vives and McCormick, 2000). While these data show an increase in correlation in the $\mathrm{KO}$ slices, this difference was small. When examining the raw traces from layer 4 and 5, very little correlation was observed suggesting that while the underlying UP state event is synchronous, the precise firing of neurons in layer 4 and 5 is, in general, not synchronous. In summary, while UP states are longer in both layers 4 and 5 of Fmr1 KO slices, the relative onset and synchrony of UP states in the two layers appear to be normal.

It has been demonstrated that the deep layers (layers 5 and 6), and not the superficial layers, are sufficient to generate UP states (Sanchez-Vives and McCormick, 2000). To determine whether the longer UP states are intrinsic to particular cortical layers, we repeated layer 5 recordings from slices containing only the deep layers of neocortex. Slices were resectioned by removal of superficial cortex (layers 1-4, Fig. 2D). UP state duration in both WT and Fmr1 $\mathrm{KO}$ resectioned slices was slightly decreased compared with normal slices but UP state frequency remained unchanged $(\sim 0.16 \mathrm{~Hz})$ suggesting that these slices were still healthy. Resectioned $\mathrm{KO}$ slices still had longer UP states in layer 5 (Fig. $2 E, F ; 549 \pm 27$ vs $733 \pm 55$ ms; WT,KO; $n=22,22$ ). This indicates that longer UP states in layer 5 of the Fmrl KO are, to a large extent, intrinsic to deep layer circuitry.

\section{Rhythmically occurring UP states are longer in Fmr1 KO mice, in vivo}

To determine whether the longer UP states we observe in Fmr $1 \mathrm{KO}$ slices were a physiologically relevant phenomenon, we recorded UP states in somatosensory cortex in vivo in anesthetized mice. As in the acute slices, UP states were indeed longer in Fmr1 KO mice and had similar durations as those observed in acute slices (Fig. $3 A, B ; 765 \pm 112$ vs $1130 \pm 112 \mathrm{~ms}, p<$ 0.05 ; WT,KO; $n=9,11$ mice). We observed no change in the frequency of UP states (Fig. $3 C ; 0.26 \pm 0.03$ vs $0.25 \pm 0.03$ $\mathrm{Hz}$; WT,KO) which is consistent with our in vitro findings where the frequency change was less salient than the duration change. Other parameters were unchanged in the KO, such as the intensity of UP state neuronal firing as defined by our rectified, filtered traces $(16.0 \pm 3.3$ vs $14.6 \pm 2.0$, WT, KO, unitless, see Materials and Methods). These results demonstrate that our observations in vitro reflect an existing condition in vivo.

The UP states in vivo probably occurred as part of the slow oscillation which has been previously been clearly observed in anesthetized cats (Steriade et al., 1993a,b) and mice (Fellin et al., 2009). Our recordings contained a distinct rhythmic component which was $<1 \mathrm{~Hz}$, and therefore reminiscent of the slow oscillation. This can be observed in the autocorrelogram of the rectified, filtered traces (Fig. 3D). When we quantified the consistency of the rhythm in our recordings, we found that UP states in vivo were more rhythmic compared with those measured in slices. This was first evident by comparing autocorrelograms of the rectified/filtered traces. The first sidepeak of the autocorrelogram was larger from recordings in vivo $(0.30 \pm 0.09 / 0.41 \pm 0.11 ; \mathrm{WT} / \mathrm{KO} ; n=9,11)$ compared with slices $(0.14 \pm 0.07 / 0.13 \pm 0.07 ; \mathrm{WT} / \mathrm{KO} ; n=18,19$; two-way ANOVA, $p<0.001$ for preparation type). The same result was observed for the second, more distant, side-peak as well $(0.30 \pm$ $0.09 / 0.38 \pm 0.11$ vs $0.15 \pm 0.05 / 0.15 \pm 0.05$; in vivo vs slice; $p<$ $0.001)$. Side-peaks always occurred in increments $>1$ s consistent with the frequency of the slow oscillation. We also measured the ratio of the SD to the average period length for each experiment, and this was lower in vivo indicating again that UP state reoccurrence was more regular, and hence more rhythmic $(0.41 \pm 0.14$ / 
$0.35 \pm 0.18$ vs $0.59 \pm 0.12 / 0.57 \pm 0.14$; in vivo vs slice; $p<0.05$, two-way ANOVA). Finally, if UP states were occurring randomly and not rhythmically, the period length distribution would be in the form of a decaying exponential (like the classical theory of mEPPs) (Johnston and $\mathrm{Wu}$, 1995). In vivo, this was not the case since the average distribution of periods was a two-tailed, single peaked function and not a decaying exponential (data not shown). This, again, was less clear in slices where the WT distribution for periods appeared more weakly two-tailed, single-peaked, but for the $\mathrm{KO}$, neither a two-tailed or decaying exponential distribution could be resolved. In summary, our in vivo data suggest that the UP state portion of the slow oscillation is lengthened in the Fmr1 KO mouse.

\section{Changes in excitatory circuitry likely contribute to longer UP states}

To begin to understand the locus of change that causes prolonged UP states in Fmrl KO mice, we next tested whether neocortical excitatory circuitry alone displays properties that would promote longer activity states. We isolated the role of excitatory circuitry in generating spontaneously active states by pharmacologically blocking $\mathrm{GABA}_{\mathrm{A}}$ and $\mathrm{GABA}_{\mathrm{B}}$ receptors using the antagonists picrotoxin $(100 \mu \mathrm{M})$ and CGP55845 $(1 \mu \mathrm{M})$, respectively. Block of these GABAergic receptors resulted in periodic epochs of persistent activity that were different from normal UP states in both duration and shape (Fig. 4). These active states were longer in the Fmr1 KO (Fig. $4 A, B ; 5.2 \pm 0.5$ vs $12.1 \pm 1.3 \mathrm{~s}$, $p<0.01$; WT,KO; $n=17,16)$, suggesting that alterations occurring in excitatory circuitry promote longer activity states. Neither the number of bursts per active state nor the frequency at which active states occurred were detectably different in the $\mathrm{KO}$ in the presence of GABA receptor antagonists (bursts/active: $5.4 \pm 1.0$ vs $9.0 \pm 1.5, p=0.06$ : frequency: $0.026 \pm 0.004$ vs $0.022 \pm 0.002$ $\mathrm{Hz}, p=0.44$; WT,KO), but the antagonist treatment itself resulted in more bursts per active state $(p<0.01)$ and a much lower frequency of occurrence $(\sim 15 \%$ of untreated, $p<0.001)$ when compared with untreated slices in Figure $1 G$. Treatment had no detectable effect on percentage of time in an active state but did increase normalized amplitude for both genotypes $(\sim 30 \%, p<$ 0.05). Additional experiments implementing $\mathrm{GABA}_{\mathrm{A}}$ receptor block alone (picrotoxin, $100 \mu \mathrm{M}$ ) also resulted in longer active states in Fmr1 KO slices $(2.0 \pm 0.2$ vs $2.8 \pm 0.3 \mathrm{~s}, p<0.05$; WT,KO; $n=$ $15,14)$ indicating that changes in $\mathrm{GABA}_{\mathrm{A}}$ signaling alone did not play a significant role in longer UP states. In summary, these data support the assertion that alterations in the recurrent excitation process among excitatory neurons play a significant role in prolonged UP state duration in the Fmr1 KO mouse.

Blocking GABAergic synapses in hippocampal slices causes a slowly occurring induction of very long persistent activity states in the CA3 region-but only in Fmr1 KO slices and not WT slices (Chuang et al., 2005). This plasticity of cell excitability requires group I mGluR activation. The long activity states in CA3 occur intermittently among very short activity states, and hence, the distribution of durations is bimodal. In a subset of slices in this study, neocortical UP states were measured before and during
picrotoxin+CGP55845 application (Fig. 4C,D; $n=10,10)$ and before and during picrotoxin application alone (data not shown, $n=7,6)$. In both sets of experiments, drug application quickly lengthened UP state duration in both WT and KO slices to the same extent and after $60 \mathrm{~min}$, the distribution of durations in a single experiment were unimodal in distribution. Therefore, our data demonstrate that the effects of inhibitory blockade on network activity states in Fmr1 KO slices are different in neocortex compared with those observed previously in the hippocampus.

\section{Longer UP states are due to deletion of Fmr1 in cortical excitatory neurons}

Next, we determined the relevant locus of Fmr1 deletion that causes longer UP states in Fmr1 KO mice. To address this question, we compared the effects of Fmr1 deletion in excitatory neurons versus inhibitory neurons.

To perform excitatory neuron-specific deletion, we crossed Emx1 Cre males with floxed Fmr1 females. In the Emx1 Cre mouse line, Cre is expressed only in cortical excitatory neurons (i.e., neocortex and hippocampus) (Iwasato et al., 2000, 2008). Using immunohistochemistry, we confirmed that $\mathrm{Cre}^{+}$: $F m r 1^{\text {flox/Y }}$ progeny had Fmr1 deleted only in cortical excitatory neurons while other genotypes showed no Fmr1 deletion (Fig. $5 A$ ). In control mice $\left(\mathrm{Cre}^{-}: \mathrm{Fmrl}^{+/ \mathrm{Y}}, \mathrm{Cre}^{+}: \mathrm{Fmrl}^{+/ \mathrm{Y}}, \mathrm{Cre}^{-}\right.$: $\left.F m r 1^{\text {flox } / Y}\right), 96 \%$ of GABAergic neurons were FMRP + while $15 \%$ of FMRP + neurons were GABAergic. Since GABAergic and glutamatergic neurons comprise $15 \%$ and $85 \%$ of all neurons in neocortex, respectively (Gonchar and Burkhalter, 1997), these immunohistochemical data are consistent with FMRP expression in both excitatory and inhibitory neurons. In mice undergoing recombination $\left(\mathrm{Cre}^{+}: F m r 1^{\text {flox } / Y}\right), 98 \%$ of GABAergic neurons were FMRP+ and 97\% of FMRP+ neurons were GABAergic. In other words, with recombination, only the GABAergic neurons were FMRP + while the neocortical excitatory glutamatergic neurons, by inference, were all FMRP-. FMRP expression in other 
A

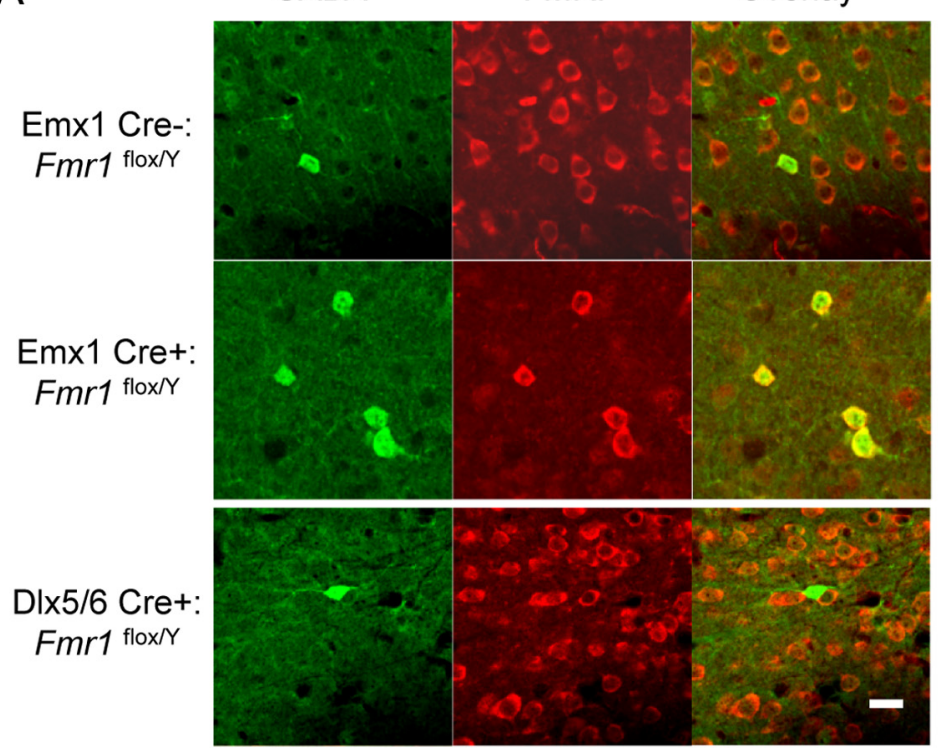

B Emx1 Cre
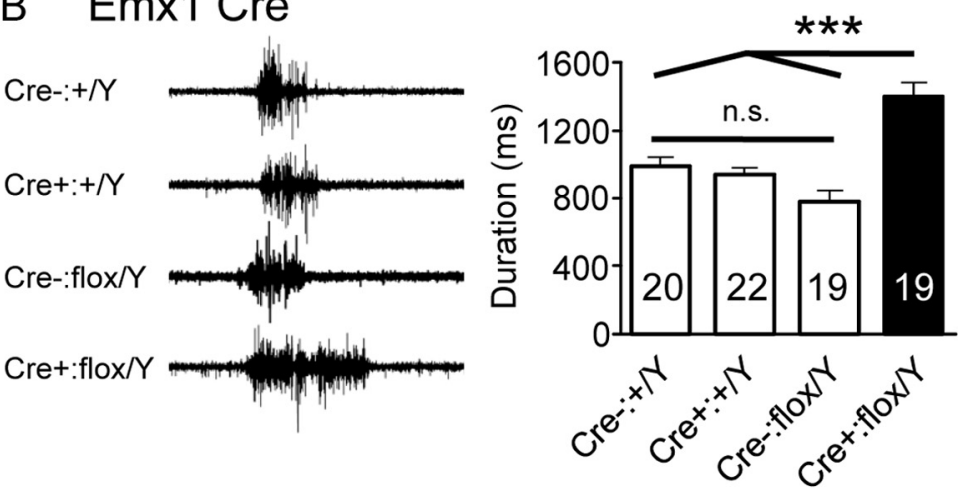

C DIx $5 / 6$ Cre
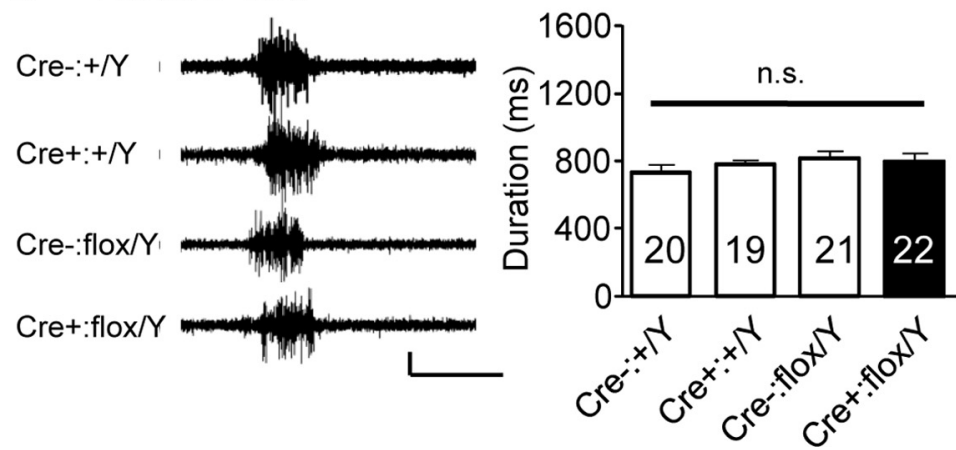

Figure 5. UP states are longer due to deletion of $F m r 1$ in neocortical excitatory neurons. $A$, Immunohistochemistry for GABA (green) and FMRP (red) shows that FMRP is expressed in both inhibitory and excitatory neurons in control animals (top row), FMRP is deleted only in excitatory neurons when recombination occurs in $E m \times 1 \mathrm{Cre}^{+}$:floxed $F m r 1$ mice (middle row), and FMRP is deleted only in inhibitory neurons when recombination occurs in $D / x 5 / 6 \mathrm{Cre}^{+}$:floxed $F m r 1$ mice (bottom row). $\boldsymbol{B}$, UP state duration is longer in slices where FMRP was deleted only in cortical excitatory neurons (black bar), thereby recapitulating the phenotype of the constitutive $F m r 1 \mathrm{KO}$. The large triangular bar indicates that the "recombined" genotype is different from all of the 3 nonrecombinant controls. C, Deletion of FMRP in inhibitory neurons did not affect UP state duration (black bar). ${ }^{* * *} p<0.001$. n.S., not significant. Calibrations: (B, C) $50 \mu \mathrm{V}, 1 \mathrm{~s}$.

noncortical structures, such as striatum and thalamus, was normal. When we examined UP states among the 4 possible genotypic combinations, we found that slices obtained from mice with deletion of Fmr1 in cortical excitatory neurons was sufficient to mimic the long UP states of Fmr1 KO mice (Fig. 5B; Cre ${ }^{-}$: $\mathrm{Fmrl}^{+/ \mathrm{Y}}=986 \pm 56, \mathrm{Cre}^{+}: \mathrm{Fmrl}^{+/ \mathrm{Y}}=939 \pm 39, \mathrm{Cre}^{-}$:
$F m r 1^{\text {flox } / Y}=776 \pm 74$, Cre $^{+}: F m r 1^{\text {flox } / Y}=$ $1398 \pm 83 \mathrm{~ms} ; p<0.001$ comparing $\mathrm{Cre}^{+}: F m r 1^{\text {flox/Y }}$ with any other genotype; $n=20,22,19,19)$. No change in UP state frequency was detected in any genotype.

Next we examined the role of Fmr1 deletion from inhibitory neurons. We crossed Dlx5/6 Cre males with floxed Fmr 1 females. In the Dlx5/6 Cre mouse line, Cre is expressed in GABAergic neurons in the forebrain, and occasionally, in some excitatory neurons in some regions of more caudoventral neocortex (Dr. John Rubenstein, personal communication; Monory et al., 2006). But somatosensory cortex is dorsal, and therefore Cre expression should be restricted to GABAergic neurons. This was confirmed by immunohistochemistry. In control mice $\left(\mathrm{Cre}^{-}\right.$:

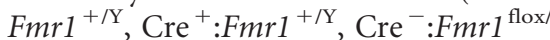
Y), $99 \%$ of GABAergic neurons were FMRP + while 14\% of FMRP + neurons were GABAergic-again consistent with expression of FMRP in both excitatory and inhibitory neurons. In mice undergoing recombination $\left(\mathrm{Cre}^{+}: F m r 1^{\text {flox/Y }}\right), 0 \%$ of GABAergic neurons were FMRP + and $0 \%$ of FMRP + neurons were GABAergic, confirming that FMRP was deleted from all GABAergic neurons (Fig. 5A). Unlike that found for deletion of Fmr1 in cortical excitatory neurons, we found that deletion of Fmrl in inhibitory neurons had no effect on UP state duration (Fig. 5C; Cre $^{-}$: $\mathrm{Fmrl}^{+/ \mathrm{Y}}=729 \pm 50, \mathrm{Cre}^{+}: \mathrm{Fmrl}^{+/ \mathrm{Y}}=$ $776 \pm 32, \mathrm{Cre}^{-}: \mathrm{Fmrl}^{\text {flox } / \mathrm{Y}}=811 \pm 49$, $\mathrm{Cre}^{+}: F m r 1^{\text {flox } / Y}=791 \pm 56 \mathrm{~ms} ; n=$ 20,19,21,22). Therefore, the longer UP states in the Fmrl KO are induced by deletion of Fmr1 in cortical excitatory neurons.

Longer UP states are rescued by genetic reduction mGluR5 signaling

Ample evidence suggests that many phenotypes in Fmr1 KO mice are due to excess group 1 metabotropic glutamate receptor (mGluR1 or mGluR5) signaling-specifically that mediated by mGluR5 (Huber et al., 2002; McBride et al., 2005; Yan et al., 2005; Dölen et al., 2007; Meredith et al., 2011). To test whether excessive activation of mGluR5 contributes to the longer UP states, we bred mGluR5 (Grm5) KO mice with Fmr1 KO mice to produce Grm5 heterozygous progeny, which has previously been shown to decrease mGluR5 protein to $60 \%$ of normal levels, and thereby presumably decreasing the signaling mediated by this receptor (Dölen et al., 2007). Using this strategy, we compared UP state duration between WT and Fmrl KO mice on both a Grm5 WT background and on a Grm5 heterozygous background. UP states measured on the Grm5 heterozygous background (Fmr1KO/Grm5Het mice) had normal duration in KO slices (Fig. 
A

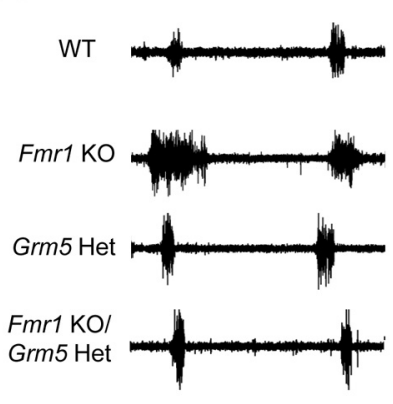

C

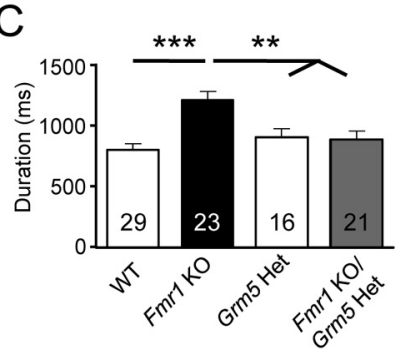

B
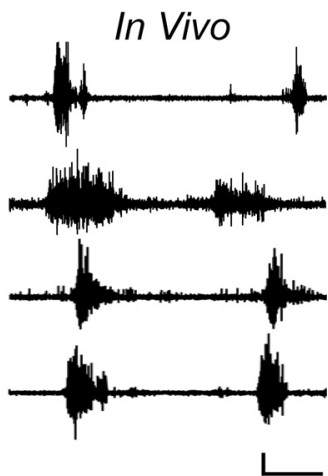

D

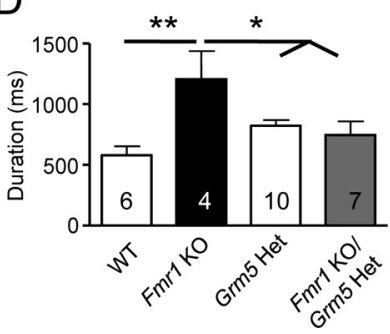

Figure 6. Genetic reduction of mGluR5 protein rescues UP state duration in Fmr1 K0 slices. $\boldsymbol{A}, \boldsymbol{B}$, Examples of traces from WT and $F m r 1 \mathrm{~K} 0$ slices $(\boldsymbol{A})$ and mice ( $\boldsymbol{B}$, in vivo) on a WT Grm 5 background (top two traces) and on a heterozygous Grm 5 background (bottom two traces). C, D, Combination of Fmr $1 \mathrm{KO}$ and Grm5 heterozygosity (gray) restores UP state duration to WT levels. Grm5 heterozygosity on a WT background has no effect on UP state duration. The large triangular bar indicates that the $K O$ duration is different from that of both WT and K0 on the Grm5 heterozygous background. ${ }^{*} p<0.05,{ }^{* *} p<0.01$, ${ }^{* * *} p<$ 0.001. Calibrations: $50 \mu V, 1 \mathrm{~s}$.

$6 A, C ; 683 \pm 57$ vs $1310 \pm 64 \mathrm{~ms}, p<0.001, n=29,23$ for WT,KO; Fmr1KO/Grm5Het $=785 \pm 67 \mathrm{~ms}, p<0.01, n=21$, when compared with Fmrl $\mathrm{KO}$ ) and in $\mathrm{KO}$ mice, in vivo (Fig. $6 B, D ; 579 \pm 74$ vs $1205 \pm 232 \mathrm{~ms}, p<0.01, n=6,4$ for WT,KO; Fmr1KO/Grm5Het $=785 \pm 67 \mathrm{~ms}, p<0.05, n=7$, when compared with Fmr1 KO). This indicated that a reduction of mGluR5 levels in the Fmr1 KO normalizes, or rescues, UP state duration. The reduction of mGluR5 dosage on a WT background does not cause any change in UP state duration in both slices (Grm5het: $828 \pm 45 \mathrm{~ms}, n=16)$ and in vivo (Grm5het: $822 \pm 46 \mathrm{~ms}, n=10$ ), indicating that a reduction of $\mathrm{mGluR} 5$ levels alone does not affect UP states. No differences in amplitude or frequency of UP states were detected across genotypes. Together, these findings implicate enhanced mGluR5 activation in contributing to longer UP states in neocortical circuits of Fmr1 KO mice.

Longer UP states are rescued by pharmacological blockade of mGluR5 signaling

To determine whether group I mGluRs play an acute, as opposed to a developmental, role in determining UP state duration, we examined the effects of specific group $1 \mathrm{mGluR}$ antagonists on UP states in WT and Fmr1 KO slices. Our strategy incorporated a 3 factor design based on 1) genotype, 2) pretreatment with the mGluR5-selective antagonist, MPEP $(10 \mu \mathrm{M})$, and 3) pretreatment with mGluR1-selective antagonist, LY367385 (100 $\mu \mathrm{M})$. This resulted in a comparison of UP state duration among 8 different groups (Fig. $7 A, B$ ). We measured UP states after 45 min of pretreatment and with drug still present. We found that MPEP, but not LY367385, had a differential effect on UP state duration which indicated that mGluR5 signaling, but not mGluR1 signaling, was acutely altered in Fmrl KO slices. This was observed by three-
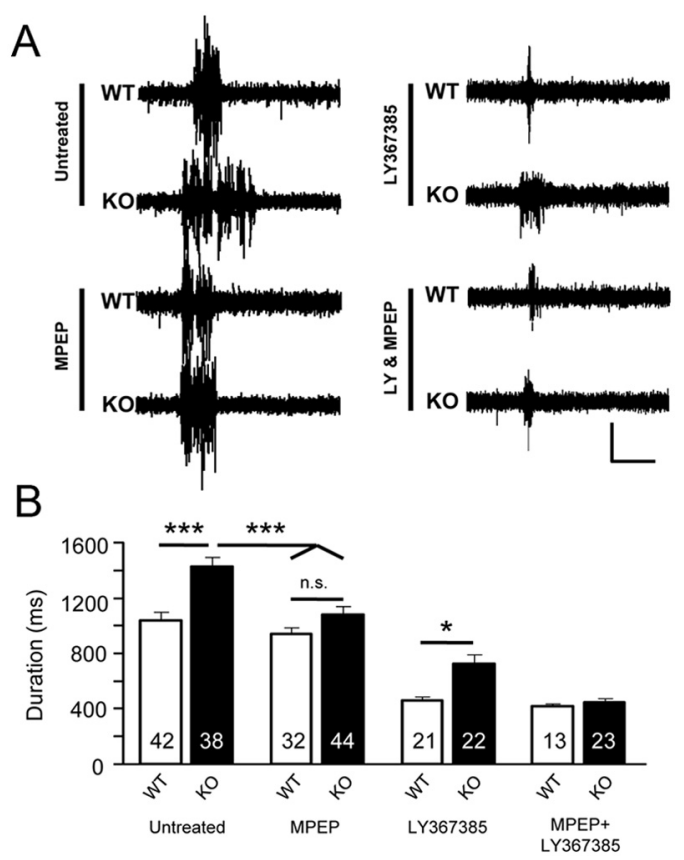

Figure 7. Pretreatment with an mGluR5 antagonist rescues UP state duration in Fmr1 K0 slices. $\boldsymbol{A}$, Examples of multiunit recordings from untreated slices and from slices after $45 \mathrm{~min}$ preincubation with an mGluR5 selective antagonist (MPEP, $10 \mu \mathrm{M}$ ) or an mGluR1 selective antagonist (LY367385, $100 \mu \mathrm{M})$. B , Summary of the effects of pretreatment on UP state duration. MPEP rescued the duration phenotype by equalizing the WT and KO UP state durations to normal WT levels. In contrast, while LY367385 significantly decreased duration in both WT and KO slices, UP states were still longer in the KO. The large triangular bar indicates that the untreated KO duration is different from that of both MPEP-treated genotypes. ${ }^{* *} p<0.01$, ${ }^{* * *} p<0.001$. n.s., not significant. Calibrations: $50 \mu \mathrm{V}, 1 \mathrm{~s}$.

way ANOVA analysis of duration data, which revealed a significant interaction between MPEP treatment and genotype $(p<0.05)$ while no interaction was detected between LY treatment and genotype.

Comparisons between individual groups (Bonferroni post hoc tests) also supported differential acute mGluR5 signaling. While untreated WT and $\mathrm{KO}$ slices had different durations (Fig. $7 B$; $1038 \pm 59$ vs $1428 \pm 63 \mathrm{~ms}, p<0.001, n=42,38)$, no difference was observed for MPEP-treated WT and KO slices ( $935 \pm 54$ vs $1076 \pm 63 \mathrm{~ms}, n=32,44)$. These same data indicated that MPEP had no detectable effect on UP state duration in WT slices, but decreased UP state duration in KO slices $(p<0.001)$. No changes in frequency of UP states were detected with MPEP treatment. Therefore, while mGluR5 signaling does not contribute to UP state duration in WT slices, it does contribute to prolonged duration in $\mathrm{KO}$ slices. In summary, these data show that the longer UP state duration phenotype in KO slices is "rescued" to normal WT durations by acutely blocking mGluR5.

In contrast to MPEP, the selective blockade of mGluR1 signaling with LY367385 had a strong but similar effect on both WT and $\mathrm{KO}$ slices. For both genotypes, UP state duration, UP state frequency, and the incidence of slices displaying UP states were reduced by $\sim 40-60 \%$ ( $p<0.05$ for all). However, duration was still longer in the KO (Fig. $7 B$; LY367385 results: $456 \pm 26$ and $720 \pm 72 \mathrm{~ms}, p<0.05, n=21,22)$. Therefore, mGluR1 function strongly regulates UP states, but does so similarly in both WT and Fmr1 KO slices.

Longer UP states do not depend on recent protein translation One function of FMRP is to suppress translation of its mRNA targets (Bassell and Warren, 2008). Therefore, it has been pro- 


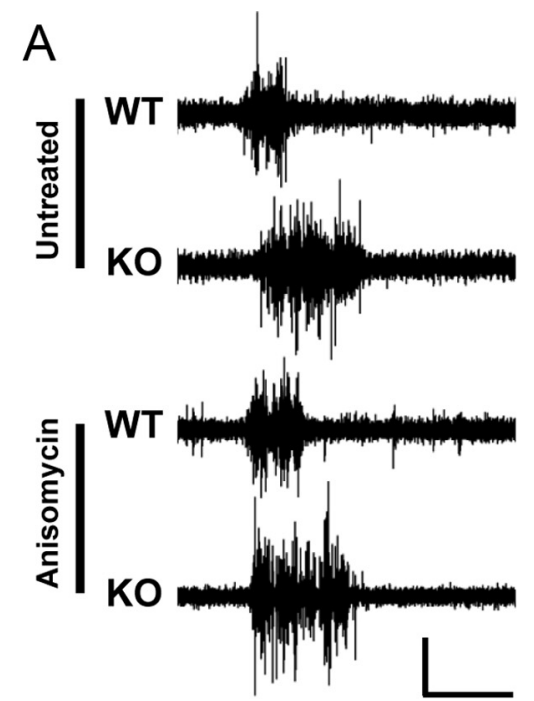

B

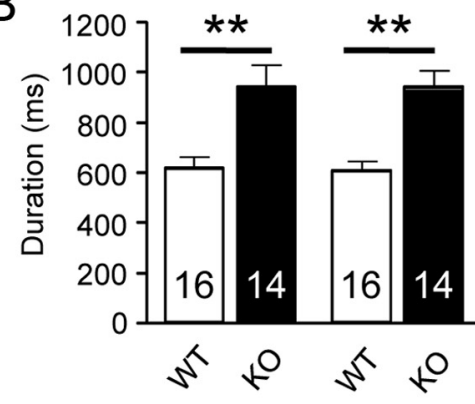

Untreated Anisomycin

Figure 8. Pretreatment with a protein translation inhibitor has no effect on WT or Fmr $1 \mathrm{KO}$ UP state duration. $A$, Examples of multiunit recordings from untreated slices and from slices after 45 min preincubation with anisomycin $(20 \mu \mathrm{M}) . \boldsymbol{B}$, While UP state duration was longer in KO slices, durations were not affected by anisomycin treatment. ${ }^{* *} p<0.01$. Calibrations: 50 $\mu \mathrm{V}, 1 \mathrm{~s}$.

posed that without FMRP, as in fragile $\mathrm{X}$ syndrome, there is excess mGluR5 driven translation which leads to phenotypes of the disease (Bear et al., 2004; Dölen and Bear, 2008). In support of this idea, mGluR5- and translation-dependent plasticity is upregulated in Fmr1 KO mice (Huber et al., 2002; Bear et al., 2004; Chuang et al., 2004). Therefore, it is possible that mGluR5 signaling causes longer UP states in KO slices through signaling to translation. If so, inhibiting protein translation would be expected equalize UP state duration among WT and KO slices similar to MPEP. We preincubated slices in the translational inhibitor, anisomycin $(20 \mu \mathrm{M})$ for $45 \mathrm{~min}$ before and during recording. This treatment had no effect on UP state duration in either WT or KO slices (Fig. 8), suggesting that at the time scale studied here, longer UP states in Fmrl KO mice are not due to mGluR5-dependent protein synthesis, but instead due to a translation independent signaling function of mGluR5.

\section{Group I mGluR activation increases UP state} duration nondifferentially

In support of the mGluR antagonist studies above, pharmacological enhancement of group I mGluR activity was sufficient to prolong UP state duration in WT and Fmrl KO slices. Application of the group I agonist, DHPG $(10 \mu \mathrm{M})$, increased the duration of UP states in WT slices (Fig. 9A, B; WT untreated: $671.7 \pm$ $103.2 \mathrm{~ms}$; WT+DHPG $826.8 \pm 131.4 \mathrm{~ms} ; p<0.01 ; n=6)$ and
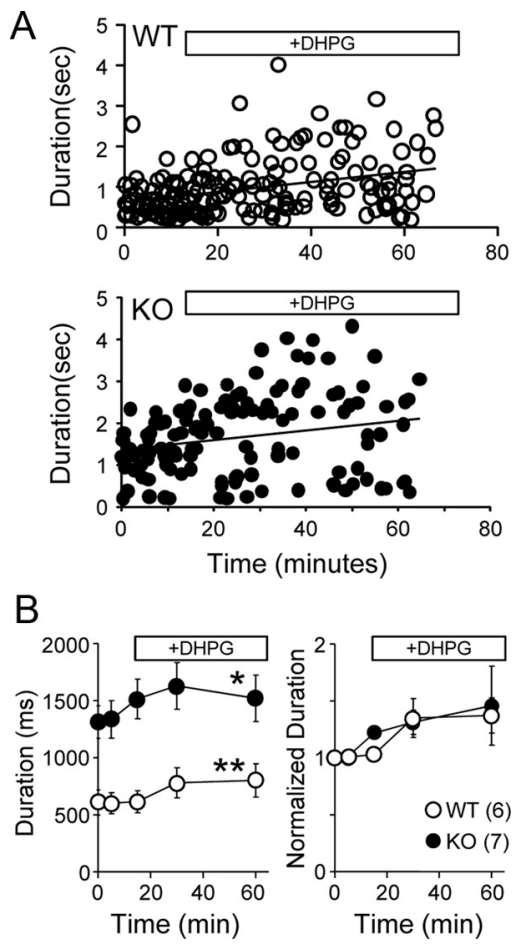

Figure 9. A group $1 \mathrm{mGluR}$ agonist lengthens UP state duration in both WT and K0 slices. $\boldsymbol{A}$, UP state duration plotted as a function of time for 1 WT and $1 \mathrm{KO}$ experiment where DHPG was applied. DHPG is added to ACSF at the 5 min time point, but the bars above the graphs depict the estimated time that DHPG reaches the slice (same applies to $\boldsymbol{B}$ ). Trendline indicates time course average. $\boldsymbol{B}$, Average time course for DHPG effect on UP state duration over all experiments plotted with raw durations (left) and durations normalized to the 0 min time point (right). ${ }^{*} p<$ $0.05,{ }^{* *} p<0.01$. $p$-values refer to an effect on duration by time (repeated-measures ANOVA).

Fmr1 KO slices (Fig. 9A,B; Fmr1 KO untreated: $1361 \pm 141.1 \mathrm{~ms}$; WT+DHPG: $1639 \pm 134.4 \mathrm{~ms} ; p<0.05 ; n=7)$. The increase in duration for both genotypes were proportionally identical (Fig. $9 B$ ), and based on the nondifferential affect of mGluR1 antagonists in Figure 7, these similar effects of DHPG may be acting through mGluR1 receptors.

We monitored UP states before and after DHPG application in these experiments since, in previous studies, DHPG caused normally quiet hippocampal CA3 region slices to display very long activity bursts interspersed with shorter bursts (bimodally distributed peaks at $0.5 \mathrm{~s}$ and at 4-10 s) (Taylor et al., 1995; Chuang et al., 2005). We did not observe this type of change in our neocortical slice preparation (Fig. 9A) indicating that different group I mGluR-regulated processes are occurring in neocortex.

\section{Discussion}

Little is known about circuit dysfunction in Fmr1 KO mice, or for that matter, in any mouse model of intellectual disability or autism. In this study, we find that spontaneously occurring UP states are longer in the mouse model of fragile $\mathrm{X}$ syndrome- - the Fmr1 KO mouse. UP states were 62\% longer in slices (combining data from Figs. $1 C, 6-8$ ) and $67 \%$ longer in vivo (combining data from Figs. 3, 6) - the latter supporting the physiological relevance of this network functional change. Neocortical excitatory neurons are probably the most significant locus of these changes since, (1) electrophysiological changes causing the longer UP states are intrinsic to neocortex, (2) activity bursts mediated by excitatory circuitry alone are longer in Fmr1 KO slices, and (3) the specific locus for Fmrl deletion that induces longer UP states is neocortical excit- 
atory neurons. Finally, we find that enhanced mGluR5 signaling underlies the longer UP states in Fmr1 KO slices.

\section{Longer spontaneously occurring UP states in Fmr1 KO mice}

We have previously demonstrated that UP states in response to thalamic stimulation were longer in Fmrl KO mice (Gibson et al., 2008). However, it was not clear to what extent this resulted from alterations in thalamic circuitry since interactions between the thalamus and neocortex can affect UP states (Rigas and CastroAlamancos, 2007; Crunelli and Hughes, 2010). Here we show that spontaneously occurring and rhythmic UP states are longer in the Fmr1 KO mouse. In slices, these UP states are mediated by neocortical circuits, independent of any thalamic pathway stimulation, and independent of the thalamus itself. The results also indicate that longer thalamically evoked UP states in Fmrl KO slices are mostly likely due to changes in neocortex and not to changes in thalamic circuitry. Because spontaneously occurring UP states are thought to be the cellular process underlying the slow oscillation during sleep (Steriade et al., 1993c), our data more directly suggest that the increase in UP state duration and time spent in the UP state (Fig. 1) may impact processes involving the slow oscillation rhythm in fragile X patients. This possible link is strengthened by our observations of longer UP states in vivo which were observed with a clear rhythmic component reminiscent of the slow oscillation.

The synchrony of UP states among different neocortical areas relies on long distance projections, but the actual generation of UP states depends on "local" network function $(\sim 1 \mathrm{~mm}$ radius) since they directly rely on recurrent synaptic excitation and inhibition among neurons in a local neocortical region (Haider and McCormick, 2009). Therefore, the longer UP states in Fmr1 KO mice are probably caused by network changes on this local scale, and more specifically, our study indicates that changes in local excitatory circuits likely play a significant role.

\section{Comparison with prolonged epileptic bursts in CA3 of Fmr1 KO mice}

Properties of persistent activity states observed in the CA3 region of the hippocampus are also altered in Fmr1 KO slices (Chuang et al., 2005). These activity states are not UP states, but instead are prolonged epileptic bursts which are induced experimentally by group I mGluR agonists in both WT and Fmrl KO slices (Taylor et al., 1995). Interestingly, they can also be induced with the application of a GABAergic antagonist which, in turn, activates group I mGluRs, but this method of induction only occurs in Fmr1 KO slices, and not in WT slices (Chuang et al., 2005). Our observations of prolonged UP states may have a common link with prolonged bursts in CA3 since both involve prolonged activity states, both depend on changes in group I mGluR signaling, and both appear to be mediated by changes in excitatory neurons. Moreover, longer UP states in the neocortex (Fig. 7), as well as epileptic bursts in the hippocampal slices obtained from Fmrl KO mice, are both reduced to normal durations with mGluR5 antagonism (Chuang et al., 2005).

But our findings differ in some key aspects. First, while persistent activity states in hippocampal CA3 slices permit the effective study of the plasticity of neuronal excitability, they are epileptic in nature and require intense pharmacological manipulations for their induction. On the other hand, UP states are widely thought to underlie aspects of neocortical function under normal conditions. Also, they do not require any special induction protocol, but instead, occur spontaneously as a baseline process. Bursts in CA3 can be induced by GABAergic receptor blockade, but only in
Fmr1 KO slices, while GABAergic receptor blockade similarly increases UP state duration in both WT and KO neocortical slices (Fig. 4). Finally, CA3 bursts require new protein synthesis, whereas prolonged neocortical UP states persist independent of new protein synthesis (Fig. 8).

Together, our data and those of Chuang et al. (2005) reveal an mGluR5-mediated hyperexcitability of circuit function in Fmr1 $\mathrm{KO}$ mice that is common to both hippocampus and neocortex. However, such circuit dysfunction is manifest differently in the two brain regions, perhaps due to the anatomy and physiology of the circuit or distinct function or localization of mGluR5 within each brain region.

\section{Role of group I mGluRs}

Our study indicates that enhanced mGluR5 signaling acutely leads to longer UP states in Fmr1 KO slices. Enhanced mGluR5 signaling is not caused by increased mGluR5 protein in Fmrl KO mice since protein level is unchanged (Huber et al., 2002; Dölen et al., 2007). Instead it appears that signaling downstream of mGluR5 activation is enhanced, and while studies have focused on enhanced mGluR-induced protein translation in the Fmrl KO (Bear et al., 2004; Osterweil et al., 2010), our data support enhanced signaling independent of protein translation as well (Fig. 8). According to this interpretation of our results, the genetic reduction of mGluR5 protein levels restores normal UP state duration (Fig. 6) by offsetting the increased signaling of individual mGluR5 receptors. Unlike mGluR5 antagonism, mGluR1 antagonism robustly suppressed the duration and frequency of UP states to a similar extent in both WT and Fmrl KO slices (Fig. 7B). These data suggest that mGluR1 regulation of UP states is normal in Fmr1 KO mice. mGluR1 and mGluR5 may regulate UP state duration through a number of mechanisms including modulation of the intrinsic excitability of neocortical neurons or synaptic function within the circuit (Kim et al., 2003; Young et al., 2004; Bianchi et al., 2009; Niswender and Conn, 2010). To our knowledge, this is the first indication for dysfunction of a specific group 1 mGluR (mGluR5, but not mGluR1) in Fmr1 KO mice.

\section{What currents mediate the longer UP states?}

The detailed mechanism of longer UP states in the Fmrl KO mice is unknown. Changes in inhibitory and excitatory circuitry may be involved, but the fact that we saw longer active states when inhibitory synapses were blocked by a GABAergic antagonist (Fig. 4) suggests that a significant component underlying longer UP states in the Fmrl KO resides in excitatory circuitry. Measurements of monosynaptic excitatory transmission in acute slices indicate that synaptic excitation among neocortical excitatory neurons is either slightly decreased or unchanged (Desai et al., 2006; Bureau et al., 2008; Gibson et al., 2008), but other studies point to increased spine number in neocortical excitatory neurons suggesting increased excitation (Bagni and Greenough, 2005). Therefore, it is unclear the role excitatory synaptic currents play in promoting longer UP states in the Fmrl KO mouse. It is also possible that there is an alteration in a nonsynaptic current in excitatory neurons that promotes longer UP states (Brown et al., 2010; Strumbos et al., 2010). Based on our findings of differential regulation of UP states by mGluR5 (Figs. 6, 7), any underlying cellular current will be modulated differentially by mGluR5 when comparing WT and KO neurons. Studies examining single-cell persistent firing in cortical neurons have reported that mGluR5 activation promotes persistent firing through a nonsynaptic membrane current (Yoshida et al., 2008; Zhang and Séguéla, 2010). 


\section{Implications of longer UP states in Fmr1 KO mice}

Because Fmr1 KO slices spend 35\% more time in the UP state (Fig. $1 D$ ), they may be considered to be more active. This implies that the neocortical circuitry may be more excitable in general, thereby affecting neocortical function in many behavioral states. This is consistent with symptoms in fragile $\mathrm{X}$ patients such as overt epilepsy, EEG abnormalities suggestive of epilepsy, and hyper-responsiveness to sensory stimuli (Hagerman et al., 1991; Miller et al., 1999; Musumeci et al., 1999; Rojas et al., 2001; BerryKravis, 2002; Incorpora et al., 2002; Castrén et al., 2003; Frankland et al., 2004). It is also consistent with Fmr1 KO mice having an increased propensity for audiogenic seizures (Chen and Toth, 2001; Nielsen et al., 2002; Spencer et al., 2006). Therefore, it is possible that the prolonged UP states themselves or the cellular mechanism that causes the longer UP states mediates the hyperexcitability in fragile $\mathrm{X}$ syndrome.

Thirty percent of children with FXS are diagnosed with autism and $1-2 \%$ of autistic children have FXS, making Fmr1 one of the leading genetic causes of autism (Kaufmann et al., 2004; Hagerman et al., 2005). Because of this strong link to autism, it is intriguing that our findings are consistent with the hypothesis that hyperexcitability in neocortical circuits underlie autism (Rubenstein and Merzenich, 2003).

UP states have been demonstrated to underlie the slow oscillation, which is a neocortical rhythm $(<1 \mathrm{~Hz})$ that occurs during the deeper stages of slow-wave sleep and anesthesia (Steriade et al., 1993b; Steriade, 1997; Amzica and Steriade, 1998). The slow oscillation during slow-wave sleep has been proposed to be involved in long-term memory consolidation in neocortex (Marshall and Born, 2007; Crunelli and Hughes, 2010). In a previous study, we have also demonstrated that inhibition during UP states is less synchronous (Gibson et al., 2008). Therefore, it is possible that the prolonged UP states with less synchronous inhibition may modify the slow oscillation in fragile X syndrome which, in turn, could impact memory consolidation. Our study suggests closer scrutiny of the slow oscillation in fragile $\mathrm{X}$ patients is warranted, but to date, while circadian rhythm and sleep problems have been reported in both fragile X patients and Fmr1 KO mice (Musumeci et al., 1991; Miano et al., 2008; Zhang et al., 2008; Kronk et al., 2010), no such data exist.

\section{References}

Agmon A, Connors BW (1991) Thalamocortical responses of mouse somatosensory (barrel) cortex in vitro. Neuroscience 41:365-379.

Amzica F, Steriade M (1998) Cellular substrates and laminar profile of sleep K-complex. Neuroscience 82:671-686.

Bagni C, Greenough WT (2005) From mRNP trafficking to spine dysmorphogenesis: the roots of fragile X syndrome. Nat Rev Neurosci 6:376-387.

Bassell GJ, Warren ST (2008) Fragile X syndrome: loss of local mRNA regulation alters synaptic development and function. Neuron 60:201-214.

Bear MF, Huber KM, Warren ST (2004) The mGluR theory of fragile X mental retardation. Trends Neurosci 27:370-377.

Berry-Kravis E (2002) Epilepsy in fragile X syndrome. Dev Med Child Neurol 44:724-728.

Bianchi R, Chuang SC, Zhao W, Young SR, Wong RK (2009) Cellular plasticity for group I mGluR-mediated epileptogenesis. J Neurosci 29:3497-3507.

Brennan FX, Albeck DS, Paylor R (2006) Fmrl knockout mice are impaired in a leverpress escape/avoidance task. Genes Brain Behav 5:467-471.

Brown MR, Kronengold J, Gazula VR, Chen Y, Strumbos JG, Sigworth FJ, Navaratnam D, Kaczmarek LK (2010) Fragile X mental retardation protein controls gating of the sodium-activated potassium channel Slack. Nat Neurosci 13:819-821.

Bureau I, Shepherd GM, Svoboda K (2008) Circuit and plasticity defects in the developing somatosensory cortex of FMR1 knock-out mice. J Neurosci 28:5178-5188.

Castrén M, Pääkkönen A, Tarkka IM, Ryynänen M, Partanen J (2003) Aug- mentation of auditory N1 in children with fragile X syndrome. Brain Topogr 15:165-171.

Chauvette S, Volgushev M, Timofeev I (2010) Origin of active states in local neocortical networks during slow sleep oscillation. Cereb Cortex 20:2660-2674.

Chen L, Toth M (2001) Fragile X mice develop sensory hyperreactivity to auditory stimuli. Neuroscience 103:1043-1050.

Chuang S, Yan Q, Bauchwitz RP, Wong RK (2004) Synaptic activation of Gp I mGluRs is epileptogenic in hippocampal slices of FMRP knock-out mice. Soc Neurosci Abstr 30:228.5.

Chuang SC, Zhao W, Bauchwitz R, Yan Q, Bianchi R, Wong RK (2005) Prolonged epileptiform discharges induced by altered group I metabotropic glutamate receptor-mediated synaptic responses in hippocampal slices of a fragile X mouse model. J Neurosci 25:8048-8055.

Crunelli V, Hughes SW (2010) The slow ( $<1 \mathrm{~Hz}$ ) rhythm of non-REM sleep: a dialogue between three cardinal oscillators. Nat Neurosci 13:9-17.

Desai NS, Casimiro TM, Gruber SM, Vanderklish PW (2006) Early postnatal plasticity in neocortex of FMR1 knockout mice. J Neurophysiol 96:1734-1745.

Dölen G, Bear MF (2008) Role for metabotropic glutamate receptor 5 (mGluR5) in the pathogenesis of fragile X syndrome. J Physiol 586:1503-1508.

Dölen G, Osterweil E, Rao BS, Smith GB, Auerbach BD, Chattarji S, Bear MF (2007) Correction of fragile X syndrome in mice. Neuron 56:955-962.

The Dutch-Belgian Fragile X Consortium (1994) Fmr1 knockout mice: a model to study fragile X mental retardation. Cell 78:23-33.

Fellin T, Halassa MM, Terunuma M, Succol F, Takano H, Frank M, Moss SJ, Haydon PG (2009) Endogenous nonneuronal modulators of synaptic transmission control cortical slow oscillations in vivo. Proc Natl Acad Sci U S A 106:15037-15042.

Frankland PW, Wang Y, Rosner B, Shimizu T, Balleine BW, Dykens EM, Ornitz EM, Silva AJ (2004) Sensorimotor gating abnormalities in young males with fragile X syndrome and Fmr1-knockout mice. Mol Psychiatry 9:417-425.

Gabel LA, Won S, Kawai H, McKinney M, Tartakoff AM, Fallon JR (2004) Visual experience regulates transient expression and dendritic localization of fragile X mental retardation protein. J Neurosci 24:10579-10583.

Gibson JR, Bartley AF, Hays SA, Huber KM (2008) Imbalance of neocortical excitation and inhibition and altered UP states reflect network hyperexcitability in the mouse model of fragile X syndrome. J Neurophysiol 100:2615-2626.

Gonchar Y, Burkhalter A (1997) Three distinct families of GABAergic neurons in rat visual cortex. Cereb Cortex 7:347-358.

Hagerman R (2002) The physical and behavioral phenotype. In: Fragile X syndrome: diagnosis, treatment, and research (Hagerman R, Hagerman P, eds), pp 3-109. Baltimore: Johns Hopkins UP.

Hagerman RJ, Amiri K, Cronister A (1991) Fragile X checklist. Am J Med Genet 38:283-287.

Hagerman RJ, Ono MY, Hagerman'PJ (2005) Recent advances in fragileX: a model for autism and neurodegeneration. Curr Opin Psychiatry 18:490-496.

Haider B, McCormick DA (2009) Rapid neocortical dynamics: cellular and network mechanisms. Neuron 62:171-189.

Huber KM, Gallagher SM, Warren ST, Bear MF (2002) Altered synaptic plasticity in a mouse model of fragile X mental retardation. Proc Natl Acad Sci U S A 99:7746-7750.

Incorpora G, Sorge G, Sorge A, Pavone L (2002) Epilepsy in fragile X syndrome. Brain Dev 24:766-769.

Irwin SA, Patel B, Idupulapati M, Harris JB, Crisostomo RA, Larsen BP, Kooy F, Willems PJ, Cras P, Kozlowski PB, Swain RA, Weiler IJ, Greenough WT (2001) Abnormal dendritic spine characteristics in the temporal and visual cortices of patients with fragile- $\mathrm{X}$ syndrome: a quantitative examination. Am J Med Genet 98:161-167.

Iwasato T, Datwani A, Wolf AM, Nishiyama H, Taguchi Y, Tonegawa S, Knöpfel T, Erzurumlu RS, Itohara S (2000) Cortex-restricted disruption of NMDAR1 impairs neuronal patterns in the barrel cortex. Nature 406:726-731.

Iwasato T, Inan M, Kanki H, Erzurumlu RS, Itohara S, Crair MC (2008) Cortical adenylyl cyclase 1 is required for thalamocortical synapse maturation and aspects of layer IV barrel development. J Neurosci 28:5931-5943.

Johnston D, Wu S (1995) Foundations of cellular neurophysiology. Cambridge, MA: MIT.

Kaufmann WE, Cortell R, Kau AS, Bukelis I, Tierney E, Gray RM, Cox C, 
Capone GT, Stanard P (2004) Autism spectrum disorder in fragile X syndrome: communication, social interaction, and specific behaviors. Am J Med Genet A 129A:225-234.

Kim SJ, Kim YS, Yuan JP, Petralia RS, Worley PF, Linden DJ (2003) Activation of the TRPC1 cation channel by metabotropic glutamate receptor mGluR1. Nature 426:285-291.

Kronk R, Bishop EE, Raspa M, Bickel JO, Mandel DA, Bailey DB Jr (2010) Prevalence, nature, and correlates of sleep problems among children with fragile X syndrome based on a large scale parent survey. Sleep 33:679-687.

Lu YM, Jia Z, Janus C, Henderson JT, Gerlai R, Wojtowicz JM, Roder JC (1997) Mice lacking metabotropic glutamate receptor 5 show impaired learning and reduced CA1 long-term potentiation (LTP) but normal CA3 LTP. J Neurosci 17:5196-5205.

Marshall L, Born J (2007) The contribution of sleep to hippocampusdependent memory consolidation. Trends Cogn Sci 11:442-450.

Marshall L, Helgadóttir H, Mölle M, Born J (2006) Boosting slow oscillations during sleep potentiates memory. Nature 444:610-613.

McBride SM, Choi CH, Wang Y, Liebelt D, Braunstein E, Ferreiro D, Sehgal A, Siwicki KK, Dockendorff TC, Nguyen HT, McDonald TV, Jongens TA (2005) Pharmacological rescue of synaptic plasticity, courtship behavior, and mushroom body defects in a Drosophila model of fragile X syndrome. Neuron 45:753-764.

Meredith RM, de Jong R, Mansvelder HD (2011) Functional rescue of excitatory synaptic transmission in the developing hippocampus in Fmr1-KO mouse. Neurobiol Dis 41:104-110.

Miano S, Bruni O, Elia M, Scifo L, Smerieri A, Trovato A, Verrillo E, Terzano MG, Ferri R (2008) Sleep phenotypes of intellectual disability: a polysomnographic evaluation in subjects with Down syndrome and Fragile-X syndrome. Clin Neurophysiol 119:1242-1247.

Mientjes EJ, Nieuwenhuizen I, Kirkpatrick L, Zu T, Hoogeveen-Westerveld M, Severijnen L, Rifé M, Willemsen R, Nelson DL, Oostra BA (2006) The generation of a conditional Fmrl knock out mouse model to study Fmrp function in vivo. Neurobiol Dis 21:549-555.

Miller LJ, McIntosh DN, McGrath J, Shyu V, Lampe M, Taylor AK, Tassone F, Neitzel K, Stackhouse T, Hagerman RJ (1999) Electrodermal responses to sensory stimuli in individuals with fragile $\mathrm{X}$ syndrome: a preliminary report. Am J Med Genet 83:268-279.

Monory K, Massa F, Egertová M, Eder M, Blaudzun H, Westenbroek R, Kelsch W, Jacob W, Marsch R, Ekker M, Long J, Rubenstein JL, Goebbels S, Nave KA, During M, Klugmann M, Wölfel B, Dodt HU, Zieglgänsberger W, Wotjak CT, et al. (2006) The endocannabinoid system controls key epileptogenic circuits in the hippocampus. Neuron 51:455-466.

Musumeci SA, Ferri R, Elia M, Colognola RM, Bergonzi P, Tassinari CA (1991) Epilepsy and fragile X syndrome: a follow-up study. Am J Med Genet 38:511-513.

Musumeci SA, Hagerman RJ, Ferri R, Bosco P, Dalla Bernardina B, Tassinari CA, De Sarro GB, Elia M (1999) Epilepsy and EEG findings in males with fragile X syndrome. Epilepsia 40:1092-1099.

Musumeci SA, Bosco P, Calabrese G, Bakker C, De Sarro GB, Elia M, Ferri R, Oostra BA (2000) Audiogenic seizures susceptibility in transgenic mice with fragile X syndrome. Epilepsia 41:19-23.

Nielsen DM, Derber WJ, McClellan DA, Crnic LS (2002) Alterations in the auditory startle response in Fmrl targeted mutant mouse models of fragile X syndrome. Brain Res 927:8-17.

Niswender CM, Conn PJ (2010) Metabotropic glutamate receptors: physiology, pharmacology, and disease. Annu Rev Pharmacol Toxicol 50:295-322.

O'Donnell WT, Warren ST (2002) A decade of molecular studies of fragile X syndrome. Annu Rev Neurosci 25:315-338.

Okun M, Naim A, Lampl I (2010) The subthreshold relation between cortical local field potential and neuronal firing unveiled by intracellular recordings in awake rats. J Neurosci 30:4440-4448.

Osterweil EK, Krueger DD, Reinhold K, Bear MF (2010) Hypersensitivity to mGluR5 and ERK1/2 leads to excessive protein synthesis in the hippocampus of a mouse model of fragile $\mathrm{X}$ syndrome. J Neurosci 30:15616-15627.

Pfeiffer BE, Huber KM (2009) The state of synapses in fragile X syndrome. Neuroscientist 15:549-567.

Rigas P, Castro-Alamancos MA (2007) Thalamocortical Up states: differen- tial effects of intrinsic and extrinsic cortical inputs on persistent activity. J Neurosci 27:4261-4272.

Rojas DC, Benkers TL, Rogers SJ, Teale PD, Reite ML, Hagerman RJ (2001) Auditory evoked magnetic fields in adults with fragile X syndrome. Neuroreport 12:2573-2576.

Rubenstein JL, Merzenich MM (2003) Model of autism: increased ratio of excitation/inhibition in key neural systems. Genes Brain Behav 2:255-267.

Sanchez-Vives MV, McCormick DA (2000) Cellular and network mechanisms of rhythmic recurrent activity in neocortex. Nat Neurosci 3:1027-1034.

Sanchez-Vives MV, Mattia M, Compte A, Perez-Zabalza M, Winograd M, Descalzo VF, Reig R (2010) Inhibitory modulation of cortical up states. J Neurophysiol 104:1314-1324.

Spencer CM, Alekseyenko O, Serysheva E, Yuva-Paylor LA, Paylor R (2005) Altered anxiety-related and social behaviors in the Fmr1 knockout mouse model of fragile X syndrome. Genes Brain Behav 4:420-430.

Spencer CM, Serysheva E, Yuva-Paylor LA, Oostra BA, Nelson DL, Paylor R (2006) Exaggerated behavioral phenotypes in Fmr1/Fxr2 double knockout mice reveal a functional genetic interaction between Fragile X-related proteins. Hum Mol Genet 15:1984-1994.

Steriade M (1997) Synchronized activities of coupled oscillators in the cerebral cortex and thalamus at different levels of vigilance. Cereb Cortex 7:583-604.

Steriade M, Nuñez A, Amzica F (1993a) A novel slow ( $<1 \mathrm{~Hz}$ ) oscillation of neocortical neurons in vivo: depolarizing and hyperpolarizing components. J Neurosci 13:3252-3265.

Steriade M, Nuñez A, Amzica F (1993b) Intracellular analysis of relations between the slow $(<1 \mathrm{~Hz})$ neocortical oscillation and other sleep rhythms of the electroencephalogram. J Neurosci 13:3266-3283.

Steriade M, McCormick DA, Sejnowski TJ (1993c) Thalamocortical oscillations in the sleeping and aroused brain. Science 262:679-685.

Steriade M, Timofeev I, Grenier F (2001) Natural waking and sleep states: a view from inside neocortical neurons. J Neurophysiol 85:1969-1985.

Stevens HE, Smith KM, Maragnoli ME, Fagel D, Borok E, Shanabrough M, Horvath TL, Vaccarino FM (2010) Fgfr2 is required for the development of the medial prefrontal cortex and its connections with limbic circuits. J Neurosci 30:5590-5602.

Strumbos JG, Brown MR, Kronengold J, Polley DB, Kaczmarek LK (2010) Fragile X mental retardation protein is required for rapid experiencedependent regulation of the potassium channel Kv3.1b. J Neurosci 30:10263-10271.

Taylor GW, Merlin LR, Wong RK (1995) Synchronized oscillations in hippocampal CA3 neurons induced by metabotropic glutamate receptor activation. J Neurosci 15:8039-8052.

Timofeev I, Grenier F, Steriade M (2001) Disfacilitation and active inhibition in the neocortex during the natural sleep-wake cycle: an intracellular study. Proc Natl Acad Sci U S A 98:1924-1929.

Verkerk AJ, Pieretti M, Sutcliffe JS, Fu YH, Kuhl DP, Pizzuti A, Reiner O, Richards S, Victoria MF, Zhang FP, Eussen BE, van Ommen GJB, Blonden LAJ, Riggins GJ, Chastain JL, Kunst CB, Galjaard H, Caskey CT, Nelson DL, Oostraa BA, et al. (1991) Identification of a gene (FMR-1) containing a CGG repeat coincident with a breakpoint cluster region exhibiting length variation in fragile X syndrome. Cell 65:905-914.

Yan QJ, Rammal M, Tranfaglia M, Bauchwitz RP (2005) Suppression of two major Fragile X Syndrome mouse model phenotypes by the mGluR5 antagonist MPEP. Neuropharmacology 49:1053-1066.

Yoshida M, Fransén E, Hasselmo ME (2008) mGluR-dependent persistent firing in entorhinal cortex layer III neurons. Eur J Neurosci 28:1116-1126.

Young SR, Chuang SC, Wong RK (2004) Modulation of afterpotentials and firing pattern in guinea pig CA3 neurones by group I metabotropic glutamate receptors. J Physiol 554:371-385.

Zhang J, Fang Z, Jud C, Vansteensel MJ, Kaasik K, Lee CC, Albrecht U, Tamanini F, Meijer JH, Oostra BA, Nelson DL (2008) Fragile X-related proteins regulate mammalian circadian behavioral rhythms. Am J Hum Genet 83:43-52.

Zhang Z, Séguéla P (2010) Metabotropic induction of persistent activity in layers II/III of anterior cingulate cortex. Cereb Cortex 20:2948-2957. 